\title{
First evidence of Klebsiella pneumoniae infection in Aceh cattle: Pathomorphology and antigenic distribution in the lungs
}

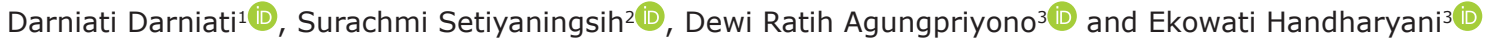

1. Animal Biomedical Sciences, Department of Veterinary Clinic Reproduction and Pathology, Faculty of Veterinary Medicine, Graduate School, IPB University, Bogor, Indonesia; 2. Department of Animal Disease and Public Health, Faculty of Veterinary Medicine, IPB University, Bogor, Indonesia; 3. Department of Veterinary Clinic Reproduction and Pathology, Faculty of Veterinary Medicine, IPB University, Bogor, Indonesia.

Corresponding author: Ekowati Handharyani, e-mail: ekowatieko@apps.ipb.ac.id

Co-authors: DD: darnizain@gmail.com, SS: surachmi@apps.ipb.ac.id, DRA: dewira@apps.ipb.ac.id Received: 26-11-2020, Accepted: 09-03-2021, Published online: 27-04-2021

doi: www.doi.org/10.14202/vetworld.2021.1007-1013 How to cite this article: Darniati D, Setiyaningsih S, Agungpriyono DR, Handharyani E (2021) First evidence of Klebsiella pneumoniae infection in Aceh cattle: Pathomorphology and antigenic distribution in the lungs, Veterinary World, 14(4): 1007-1013.

\begin{abstract}
Background and Aim: Klebsiella pneumoniae is an emerging zoonotic and foodborne pathogen worldwide. Hypervirulent K. pneumoniae (hvKp) was reported as the causative agent of bovine mastitis. This is the first study in Indonesia that has been conducted to determine the capsular serotype of K. pneumoniae, pulmonary gross pathology and histopathology, and distribution of hvKp in the lungs of Aceh cattle.

Materials and Methods: The presence of K. pneumoniae in Aceh cattle was investigated in two slaughterhouses in Banda Aceh and Aceh Besar, Indonesia. Lung tissues with gross pathological lesions were collected from 15 cattle presenting with depression, dehydration, or cachexia. The confirmation and capsular serotyping of $K$. pneumoniae isolates were performed using polymerase chain reaction. The tissues were stained with hematoxylin-eosin and immunohistochemistry to observe the histopathological lesions and the distribution of the hvKp antigens.

Results: The pneumonic lesions identified in the lungs of Aceh cattle included hyperemia, hemorrhage, consolidation, and atelectasis. K. pneumoniae was isolated in all 15 lung tissues with pathological pneumonic lesions. Two patterns of infection were observed histopathologically. Acute infection was characterized by hyperemia, inflammatory cell infiltration, hemorrhage, bronchiolar epithelium hyperplasia, bronchial and bronchiolar obstruction with purulent exudates, edema, and atelectasis. On the other hand, chronic infection was defined by macrophage infiltration, emphysema, bronchial dilatation, pleural fibrosis, and alveolar wall thickening by interstitial fibrosis. Immunohistochemical staining using monospecific antisera induced by the hvKp isolate confirmed the presence of $K$. pneumoniae-specific antigens in the acute infection, predominantly in the bronchiolar, vascular, and alveolar areas. In contrast, generally diffuse infiltrates were found in the pleura and interstitial alveolar areas in chronic infection.
\end{abstract}

Conclusion: hvKp can be detected in the lungs of Aceh cattle, representing acute and chronic infections. The distribution of Klebsiella antigens in the lung tissue was consistent with the histopathological findings.

Keywords: Aceh cattle, capsular serotyping, histopathology, immunohistochemistry, Klebsiella pneumoniae, lung.

\section{Introduction}

Klebsiella pneumoniae is a facultative anaerobic, Gram-negative, rod-shaped, non-motile encapsulated bacterium capable of fermenting glucose and lactose, which can cause infection in humans, animals, and plants $[1,2] . K$. pneumoniae were classified into classical K. pneumoniae and hypervirulent $K$. pneumonia (hvKp) strains based on their genotypic and phenotypic biomarkers [3]. hvKp phenotypes are associated with the production of a thick polysaccharide capsule that contributes to the increased virulence and pathogenicity. The capsule is considered

Copyright: Darniati, et al. Open Access. This article is distributed under the terms of the Creative Commons Attribution 4.0 International License (http://creativecommons.org/licenses/ by/4.0/), which permits unrestricted use, distribution, and reproduction in any medium, provided you give appropriate credit to the original author(s) and the source, provide a link to the Creative Commons license, and indicate if changes were made. The Creative Commons Public Domain Dedication waiver (http:// creativecommons.org/publicdomain/zero/1.0/) applies to the data made available in this article, unless otherwise stated. the most important virulence factor in K. pneumoniae, which is required to maintain survival in the environment and within the host $[4,5]$. The polysaccharide capsule is also important because it favors the attachment to the cell surface and the formation of biofilms [6-9]. In addition, lipopolysaccharides (LPSs) mediate the resistance to complement-mediated and neutrophil-mediated bactericidal activity, as well as the resistance to multiple antibiotics activity $[9,10]$.

$K$. pneumoniae is considered one of the most important pathogens in public health because they are animal-borne bacterial pathogens (zoonoses) [1]. In humans, $K$. pneumoniae has been associated with pneumonia, urinary tract infections, bacteremia, and liver abscess, primarily in immunocompromised hosts $[11,12]$. However, hypervirulent strains have been reported to cause various severe infections in immunocompetent and young healthy individuals [13]. hvKp has been implicated in causing pulmonary lesions in animals, such as suppurative bronchopneumonia in sheep [14], purulent bronchopneumonia 
in sea lions [15,16], pneumonia in Boer goats [17], and pneumonia and bacteremia in non-human primates [18]. On the other hand, hvKp infection in cattle is widely recognized as the causative agent of mastitis [19]. However, there was little evidence of $K$. pneumoniae association with bovine respiratory disease. $K$. pneumoniae was isolated from $25 \%$ out of 150 pneumonic lungs of cattle in a slaughterhouse in Nigeria [20]. To the best of our knowledge, one study published the isolation of KP in only one pneumonic lung of Bali cattle in Indonesia [21], but the capsular serotypes, histopathology, and distribution of the bacteria are not available in the literature. Recently, 12 isolates belonging to hvKp have been detected from cattle nasal swabs in Southwest China [1]. However, the information about the capsular serotypes of $K$. pneumoniae in cattle is still limited, and the pathological evidence has been poorly investigated.

Information regarding $K$. pneumoniae infection in cattle respiratory system is insufficient; therefore, a study related to this topic is important to recognize the prevalence and pathogenesis of infection in cattle. This preliminary study aimed to determine the capsular serotype of K. pneumoniae, pulmonary gross pathology and histopathology, and distribution of hvKp in pneumonic lungs of Aceh cattle.

\section{Materials and Methods}

\section{Ethical approval}

This research has been approved by the Animal Care and Use Committee of Research and Community Services Institution, IPB University, Bogor, with approval number: 144/KEH/SKE/VII/2019.

\section{Study period and location}

The study was conducted from August 2019 to April 2020 at the Microbiology and Pathology Laboratory, Faculty of Veterinary Medicine, IPB University, Bogor, Indonesia.

\section{Animal and sample collection}

Pneumonic lungs of 15 Aceh cattle from two slaughterhouses with any signs of depression, dehydration, and cachexia were included in this study. The samples were collected immediately after slaughter and evisceration. The lungs with gross lesions such as hyperemia, hemorrhage, consolidation, and atelectasis were collected aseptically. The specimens were cut into two pieces; one cut was dipped into brain heart infusion broth (BHIB) for microbiology examination, while the other was fixed into $10 \%$ neutral formalin buffer. Lung specimens in BHIB were kept at $-20^{\circ} \mathrm{C}$ for microbiological examination.

\section{Bacterial isolation}

The microbiological examination was carried out at the Microbiology Laboratory of the Faculty of Veterinary Medicine, IPB University, Bogor. Lung specimens were enriched overnight in BHIB at $37^{\circ} \mathrm{C}$ for $48 \mathrm{~h}$, followed by streaking onto MacConkey agar and blood agar plates. The inoculated plates were anaerobically incubated in a lighted candle jar to reduced aerobiosis. Every single colony was identified by colony morphology, string test, Gram staining, capsule staining, carbohydrate fermentation (sucrose, mannitol, lactose, and glucose), and biochemical tests (indole, citrate, TSIA, catalase, and urease).

Polymerase chain reaction (PCR)-based identification Identification of suspected colonies was performed by rроB (RNA polymerase $\beta$ subunit) PCR amplification specific for $K$. pneumoniae. Nucleic acids were extracted from each colony using the boiling method. Briefly, one colony was resuspended in $50 \mu \mathrm{L}$ nuclease-free water, heated at $100^{\circ} \mathrm{C}$ for $10 \mathrm{~min}$, and the supernatant was collected by centrifugation at $12.000 \mathrm{~g}$ for $5 \mathrm{~min}$. The rpoB PCR was performed according to Chander et al. [22] to detect 108 bp using a primerpair ofF-CAACGGTGTGGTTACTGACG and R-TCTACGAAGTGGCCGTTTTC. Amplification was performed in Bio-Rad thermal cycler (BioRad Laboratories, Inc., Hercules, CA, USA) using the following amplification conditions: $95^{\circ} \mathrm{C}$ for $3 \mathrm{~min}$; 30 cycles of $95^{\circ} \mathrm{C}$ for $30 \mathrm{~s}, 55^{\circ} \mathrm{C}$ for $90 \mathrm{~s}$, and $72^{\circ} \mathrm{C}$ for $90 \mathrm{~s}$; and a final step at $72^{\circ} \mathrm{C}$ for $10 \mathrm{~min}$. The PCR products were separated in $1.5 \%$ agarose gel electrophoresis for $30 \mathrm{~min}$ at $120 \mathrm{~V}$ and visualized using UV transilluminator.

\section{Histopathology}

Histopathological examination was carried out at the Pathology Laboratory of the Faculty of Veterinary Medicine, IPB University, Bogor. The histopathological examination procedure followed a method as described by Zhou and Moore [23]. The fixed lung specimens were processed overnight for dehydration, clearing, and impregnation using an automatic tissue processor. The tissues were embedded in paraffin blocks using an embedding station and serial sections of 4-5 $\mu \mathrm{m}$ thickness were cut using a microtome. Tissue sections were stained with hematoxylin-eosin. The histopathological lesions assessment was done descriptively according to the presence of pneumonia signs. Acute bacterial infection was characterized by the presence of inflammatory cell infiltration, hyperemia, edema, hemorrhage, and atelectasis. Meanwhile, the chronic infection was determined by the existence of emphysema, bronchiole dilatation, and fibrosis. The severity of the lesion was graded with the following criteria: Focal lesion distribution (low severity), multifocal (moderate severity), and diffuse (high severity).

\section{Immunohistochemistry (IHC)}

Monospecific antisera produced by immunizing rabbits using hvKp isolates followed by absorption against non-hvKp were used. The tissue section that has been attached to a microscopic slide using polyL-lysine $1 \%$ was deparaffinized, rehydrated with distilled water, and put under flowing with tap water for $5 \mathrm{~min}$, followed with phosphate-buffered saline 
(PBS) Tween. The method followed the protocol that was supplied with the mouse and rabbit specific HRP/ DAB (ABC) detection IHC kit (ab64264, Abcam, Cambridge, UK). Blocking endogenous activity was performed with immersion in 3\% hydrogen peroxide at room temperature $\left(20-25^{\circ} \mathrm{C}\right)$ for $15 \mathrm{~min}$, followed by three washes in PBS Tween. Non-specific protein binding was blocked using $10 \%$ normal goat serum at $20-25^{\circ} \mathrm{C}$ for $30 \mathrm{~min}$ and washed with PBS Tween. Tissue sections were incubated overnight at $4^{\circ} \mathrm{C}$ with rabbit anti-K. pneumoniae polyclonal antibodies and followed by incubation with secondary antibody Dako REAL ${ }^{\mathrm{TM}}$ envision ${ }^{\mathrm{TM}} / \mathrm{HRP}$, rabbit/ mouse (ENV) for $30 \mathrm{~min}$. The streptavidin-HRP was applied for $30 \mathrm{~min}$ at $20-25^{\circ} \mathrm{C}$, and the section was visualized using Dako REAL ${ }^{\mathrm{TM}} \mathrm{DAB}+$ chromogen in Dako REALTM substrate buffer. The section was counterstained with Mayer's hematoxylin and mounted with Aquamount.

\section{Results}

\section{Bacterial isolation and identification}

hvKp was isolated in all 15 pneumonic lungs. $K$. pneumoniae were characterized as non-hemolytic gray-white mucoid colonies on blood agar and small pink mucoid (lactose fermenter) colonies on MacConkey agar. The bacterial isolates were rodshaped and pink color in the Gram staining test. Biochemical tests showed negative results for indole, motility, and methyl red tests; and positive results for citrate, Voges-Proskauer, TSIA (A/A), and sugar fermentation tests. The hypermucoviscosity phenotype was defined by the string test, in which the formation of viscous strings greater than $5 \mathrm{~mm}$ in length was observed on spreading with an inoculation loop. The species identity was confirmed by the presence of 108 bp band of the $r p o B$ region.

\section{Gross pathological lesion}

The main lung lesions observed in most of the cases were pneumonic patches with hyperemia, hemorrhages, atelectasis, and consolidation of the left and right ventral lobes with dark red-discolored areas to gray-pink appearance (Figures-1 and 2). Emphysema was detected in some of the lung tissue samples.

\section{Histopathology}

The general tissue responses to hvKp were observed in all 15 lung samples, which could be attributed to acute and chronic pneumonia with purulent bronchopneumonia and interstitial bronchopneumonia. Acute inflammatory responses were characterized by the presence of hyperemia (congestion), edema, and hemorrhage within intra-alveolar spaces (Figure-3b), and inflammatory cells infiltration in the alveolar spaces (Figure-3c). The alveolar lumen of pneumonic lungs showed narrowing compared with normal lungs (Figure-3a). In addition, bronchiolar epithelium hyperplasia, peribronchiolar infiltration with inflammatory cells, bronchial and bronchiole

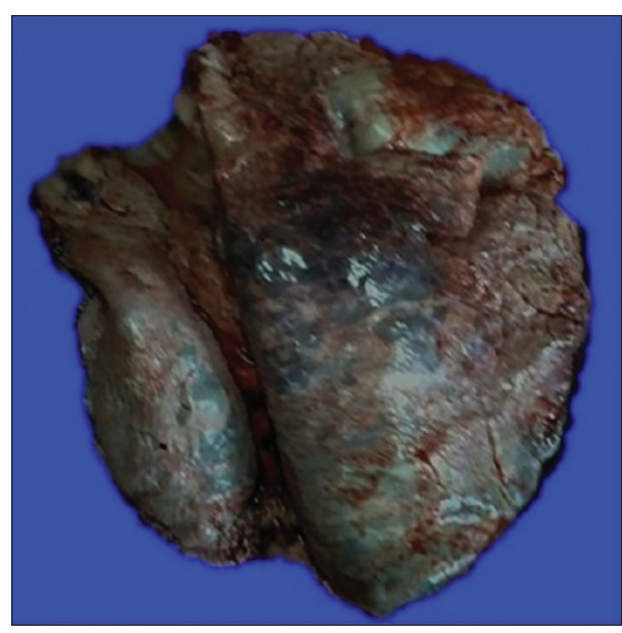

Figure-1: Dark red discolored area in acute form.

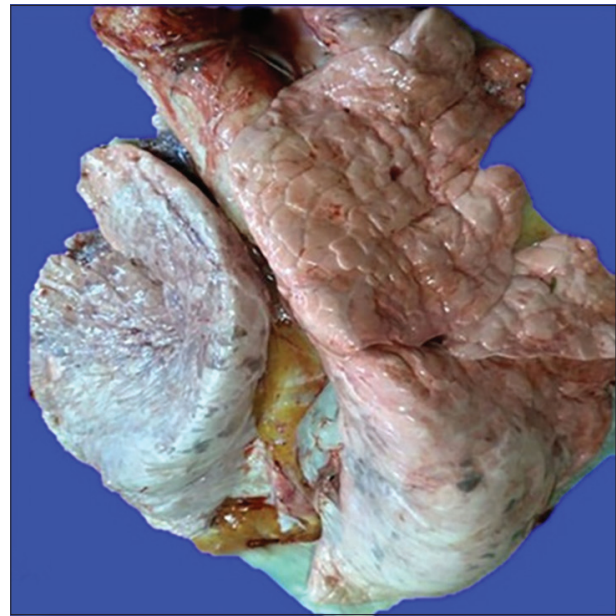

Figure-2: Gray-pink appearance in chronic form.

obstruction with purulent exudate (Figure-3d), and collapse of lung or atelectasis were evident (Figure-3e). Microscopically, all cattle had fibrinosuppurative broncho- or interstitial bronchopneumonia affecting much of the cranioventral aspect of the lung.

In contrast, characteristics of chronic pneumonia such as thickened alveolar walls by interstitial tissue fibrosis (Figure-4b), pleural fibrosis (Figure-4c), and lymphocytes and macrophages infiltration, as well as bronchiole dilatation (Figure-4d) and emphysema were observed in several samples (Figure-4e). Destruction of epithelium appears in bronchitis compared to normal tissue (Figure-4a).

\section{IHC}

hvKp antigens were present in the bronchiolar and alveolar lung epithelia, interstitium, and pleura. Specific immunoperoxidase labeling associated with the hvKp antigen was most frequently found in the cytoplasm of bronchiolar epithelial cells, neutrophils, macrophages, cytoplasm of the pneumocytes type II. In areas with encapsulated bacteria, $K$. pneumoniae antigen was rarely detected inside inflammatory cells. On the other hand, the cytoplasm of macrophages containing phagocytized debris of $K$. pneumoniae was observed in the area where bacteria were partially 


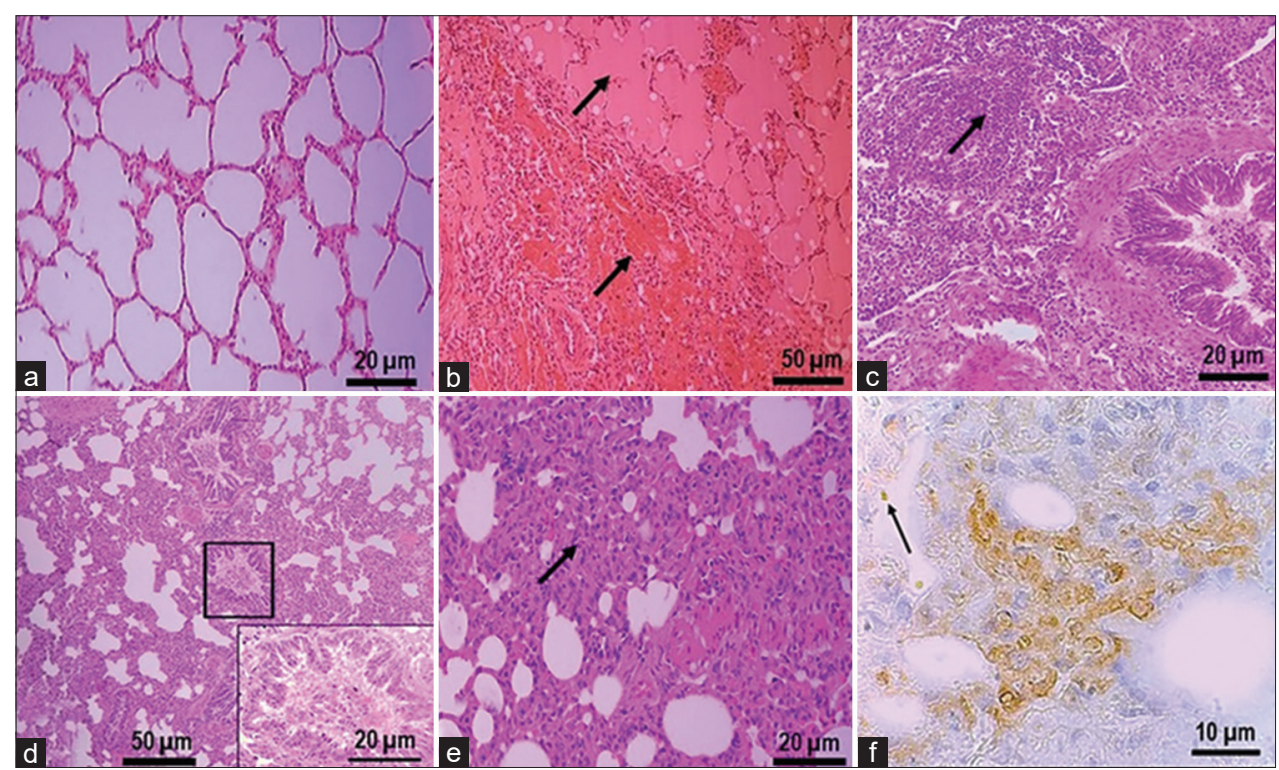

Figure-3: Lung histopathological lesions with suggested in acute infection. (a) Normal alveoli. (b) Lung edema and hemorrhage. (c) Inflammatory cell infiltration within the alveoli. (d) Bronchiolar epithelial hyperplasia (box) and obstruction with purulent exudate. (e) Atelectasis. (f) Klebsiella pneumoniae within macrophages of alveolar wall. $K$ pneumoniae with intact capsule in areas less affected by inflammation (arrow).

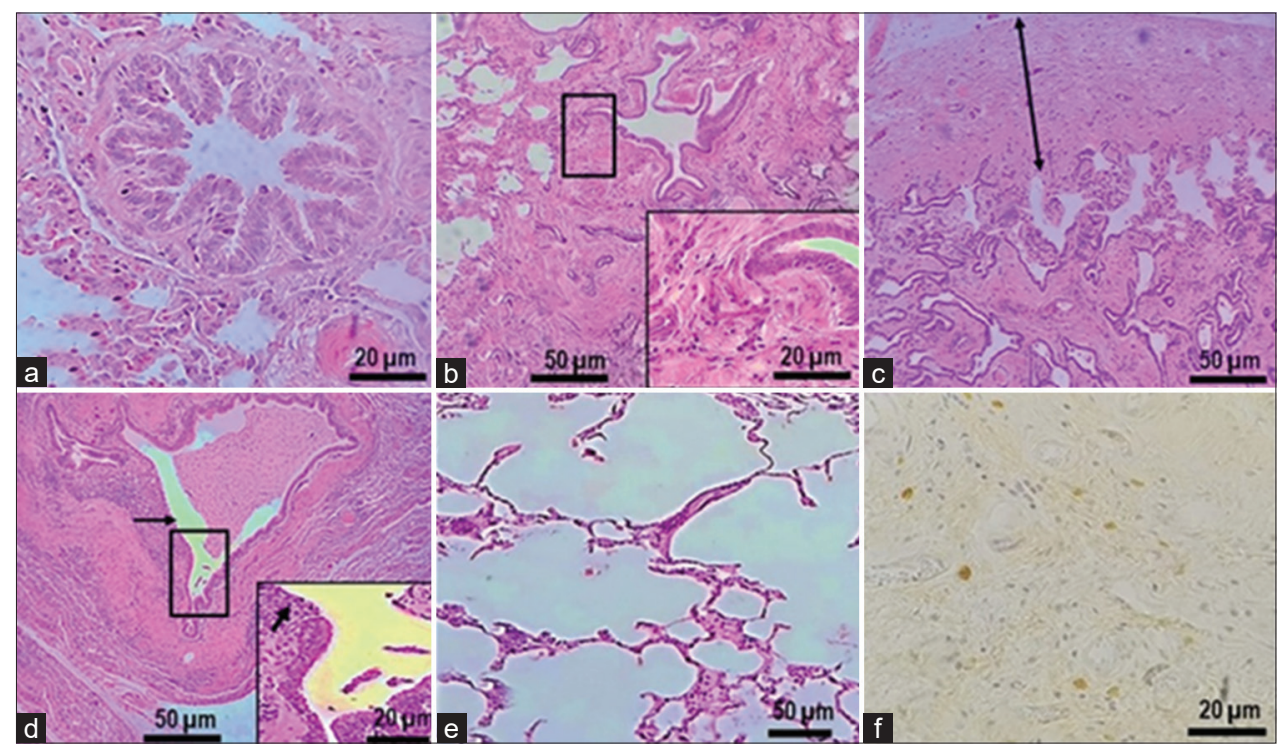

Figure-4: Lung histopathological lesions in chronic infection. (a) Normal alveoli and bronchiole. (b) Alveolar thickening with interstitial fibrosis. (c) Pleural fibrosis. (d) Bronchial dilatation. (e) Emphysema. (f) Klebsiella pneumoniae in interstitial lung.

disrupted or lacking peripheral halos. In lungs with acute lesions, the distribution of $K$. pneumoniae antigens was mainly in the bronchiolar, vascular, and alveolar areas (Figure-3f), in contrast to largely diffuse infiltrates in the fibrotic areas of lungs with chronic lesions (Figure-4f).

\section{Discussion}

Aceh cattle are indigenous Indonesian beef cattle that are raised with traditional to semi-intensive husbandry practices. However, rural farming with traditional methods is often faced with disease problems, especially respiratory diseases. Respiratory disease was frequently reported and often associated with pasteurellosis based on serological testing, although
Pasteurella multocida as the actual causative agent was predominantly negative by PCR testing (personal communication).

In this study, we report the isolation of $K$. pneumoniae in all 15 pneumonic lungs, which is confirmed by tracing the rроB gene. All isolates can be categorized as hvKp based on the string formation in blood agar. The $r p o B$ gene that encodes the beta subunit of the bacterial RNA polymerase has been effectively used to identify K. pneumoniae [22], and it is more discriminative than the 16S rRNA gene, allowing identification at the species or even subspecies level of $K$. pneumoniae [24].

$K$. pneumoniae is an opportunistic pathogen predominantly affecting immunocompromised or elderly 
patients. Although $K$. pneumoniae is primarily known as the cause of environment-derived bovine mastitis, upper respiratory tract infection of dairy cattle with hvKp has been reported [1]. The presence of K. pneumoniae in pneumonic lungs has been reported as the second most prevalent after Staphylococcus aureus in mixed bacterial respiratory infection in cattle [20]. The incidence of hvKp in Aceh cattle lungs is presumably due to inhalation of pathogens from the upper respiratory tract.

Airway invasion was influenced by various host factors and the capability of $K$. pneumoniae pathotype to inhibit host defense responses by immune evasion strategies. hvKp employs many strategies to survive and protect itself from the host immune response [25]. K. pneumoniae has been associated with two forms of pneumonia in humans, acute and chronic infection. The acute form usually develops quickly and lasts less than 2 weeks, manifesting with symptoms such as high fever, dry cough, chest pain, and dyspnea [26]. In contrast, the chronic infection develops slowly, similar to other chronic lung infections, and frequently exhibited as a chronic productive cough [27]. Our finding suggested the involvement of hvKp in acute and chronic respiratory infection in Aceh cattle.

Acute pneumonia was marked by hyperemia (intense capillary congestion), polymorphonuclear leukocyte infiltrates, edema, alveolar hemorrhage, bronchiolar hyperplasia, and purulent exudates within the bronchus and bronchioles. In the early stage of the respiratory infection, a bacterial pathogen has to escape the first mechanical defense of mucociliary clearance in the bronchus $[28,29]$. Loss of cilia and ciliated cells in small bronchi and bronchioles has been shown to be responsible for the host defense failure against hvKp colonization through biofilm formation, and allows bacteria to access the lungs [25]. Infection of hvKp in the airways triggers hyperplasia of bronchiole cells, neutrophils infiltration, and purulent exudate production, leading to the obstruction of the bronchi and bronchioles. The airway constriction and obstruction trap the air in the lung periphery and eventually give rise to atelectasis. Simultaneously, cell death and LPS activation during bacterial infection will induce prostaglandins $\left(\mathrm{PGE}_{2}\right)$ synthesis. $\mathrm{PGE}_{2}$-mediated increase in microvascular permeability and vasodilation causes increased blood flow (hyperemia) and facilitates the recruitment of inflammatory cells [30]. Neutrophils, macrophages, and mast cells release pro-inflammatory mediators such as tumor necrosis factor-alpha $(\mathrm{TNF}-\alpha)$, interleukin 6 , and interferon-gamma to induce the expression of adhesion molecules in the endothelium and promote neutrophils attachment to the vascular endothelium [31]. Furthermore, pro-inflammatory mediators will increase vascular permeability and immobilization of circulating neutrophils to the site of infection [32]. Subsequently, this vascular permeability causes plasma protein extravasation, causing edema. In addition to vascular permeability, pulmonary hemorrhage and edema can be caused by lung vascular injury [33].

Colonization of hvKp through biofilm formation facilitates evasion of the host defense system and resistance to antimicrobial agents, which most likely leads to chronic infection [34]. Our study suggests the presence of chronic hvKp lung infection in Aceh cattle as characterized by moderate thickening of alveolar walls, extensive interstitial fibrosis, infiltration of lymphocytes and macrophages, emphysema, and bronchiole dilatation. The previous study reported that $K$. pneumoniae invasion of sheep lungs causes hyperplasia of pneumocytes type II and infiltration of inflammatory cells such as lymphocytes and macrophages to the infection area, causing alveolar thickening [35]. In the case of chronic inflammation, alveolar tissue injury can occur due to the damage of alveolar epithelial cells and basal membrane, endothelial cell disruption, and in severe cases, can cause damage of elastic fibers. Damage to endothelial cells will cause the leakage of protein-rich fluid into the alveolar space accompanied by myofibroblast migration from the interstitium, which results in the formation of immature collagenous tissue [36]. If inflammation persists, lung infection results in fibrotic remodeling and gives rise to a loss of tissue integrity, alveolar collapse, and irreversible fixed fibrosis, which can lead to total lung damage [37,38].

Histological examinations of the lungs of Aceh cattle showed pleural thickening marked with the presence of connective tissue, suggesting pleural fibrosis, which can be caused by severe inflammation that is common in chronic infections. The pleural injury will induce the activation of mesothelial cells, which together with inflammatory cells in the pleural space will release fibroblast growth factors such as transforming growth factor-beta (TGF- $\beta$ ), Basic fibroblast growth factor, platelet-derived growth factor, and connective tissue growth factor. In addition, pleural injury induces induction of the coagulation pathway and inhibition of fibrinolysis which mediated pleural fibrosis [39]. Pleural thickening characterized by marked expansion of fibrous tissue was demonstrated by Klebsiella spp. infection in horses [40].

Emphysema was evident in this study and was mostly combined with fibrosis. These could be attributable to constant and severe inflammation, which causes airflow obstruction, tissue destruction, extensive tissue structural alteration, and overexpression of immune mediators, such as TNF- $\alpha$ and TGF- $\beta$. Infiltration of inflammatory cells into the alveolar walls triggers alveoli destruction by neutrophil elastase and macrophage proteolytic enzymes, resulting in the enlargement of air spaces due to the degradation of the extracellular matrix, specifically collagen and elastin, in the alveoli $[41,42]$. Immunohistochemical staining demonstrated that 
the distribution of Klebsiella antigens was consistent with histopathological findings. In acute infection, hvKp antigens were detected in the alveolar, vascular, and bronchiolar areas, while in chronic infection, antigens were predominantly present in areas of active fibrosis. Furthermore, macrophages were rarely present in the areas having encapsulated bacteria, in contrast to areas with non-capsulated or disrupted bacteria, which were surrounded by macrophages containing antigens. Similar findings in sea lions were also reported [16], substantiating the importance of $K$. pneumoniae capsular antigen in escaping host immune responses, such that they can invade the lower respiratory system. Thus, the observations of the histopathological and immunohistochemical findings in the lungs of Aceh cattle suggest the involvement of hvKp presence in acute $(9 / 15 ; 60 \%)$ and chronic $(6 / 15 ; 40 \%)$ infections; however, the role of other respiratory pathogens such as Mycoplasma, Mannheimia haemolytica, and P. multocida has remained to be established.

\section{Conclusion}

hvkp can be detected in the lungs of Aceh cattle representing acute and chronic infections. Acute infection was characterized by alveolar hyperemia and hemorrhage, neutrophils infiltration, and atelectasis, while the chronic infection was characterized by thickened alveolar walls, interstitial and pleural fibrosis, emphysema, and bronchiole dilatation. The distribution of Klebsiella antigens in lung tissue was consistent with histopathological findings. In view of all the findings, further investigations are necessary to determine infection of $K$. pneumoniae, alone or together with other potential pathogens in disease pathogenesis and progression.

\section{Authors' Contributions}

DD executed the work (sample collection and examination, data analysis, and writing manuscript). SS participated in the conception and microbiological study design, data analysis and interpretation, and drafting the manuscript. DRA analyzed and interpreted the pathological data and revised the manuscript draft. EH conceptualized, designed, analyzed, and interpreted the pathological data. All authors read and approved the final manuscript.

\section{Acknowledgments}

The authors are grateful to IPB University, Bogor and Syiah Kuala University for the supports during this study. This research was funded by the Ministry of Research, Technology, and Higher Education of the Republic of Indonesia for scholarship and research (Grant No. 2794/A2.1/KP/2018).

\section{Competing Interests}

The authors declare that they have no competing interests.

\section{Publisher's Note}

Veterinary World remains neutral with regard to jurisdictional claims in published institutional affiliation.

\section{References}

1. Cheng, F., Li, Z., Lan, S., Liu, W., Li, X., Zhou, Z., Song, Z., Wu, J., Zhang, M. and Shan, W. (2018) Characterization of Klebsiella pneumoniae associated with cattle infections in Southwest China using multi-locus sequence typing (MLST) antibiotic resistance and virulence-associated gene profile analysis. Braz. J. Microbiol., 49(1): 93-100.

2. Martin, R.M. and Bachman, M.A. (2018) Colonization, infection, and the accessory genome of Klebsiella pneumoniae. Front. Cell Infect. Microbiol., 8(4): 1-15.

3. Russo, T.A., Olson, R., Fang, C.T., Stoesser, N., Miller, M. MacDonald, U., Hutson, A., Barker, J.H., La Hoz, R.M. and Johnson, J.R. (2018) Identification of biomarkers for differentiation of hypervirulent Klebsiella pneumoniae from classical K. pneumoniae. J. Clin. Microbiol., 56(9): e00776-e00818.

4. Russo, T.A. and Marr, C.M. (2019) Hypervirulent Klebsiella pneumoniae. Clin. Microbiol. Rev., 32(3): 1-42.

5. Choby, J.E., Howard-Anderson, J. and Weiss, D.S. (2020) Hypervirulent Klebsiella pneumoniae-clinical and molecular perspectives. J. Internal Med., 287(3): 283-300.

6. Struve, C. and Krogfelt, K.A. (2003) Role of capsule in Klebsiella pneumoniae virulence: Lack of correlation between in vitro and in vivo studies. FEMS Microbiol. Lett., 218(1): 149-154.

7. Effah, C.Y., Sun, T., Liu, S. and Wu, Y. (2020) Klebsiella pneumoniae: An increasing threat to public health. Ann. Clin. Microbiol. Antimicrob., 19(1): 1-9.

8. Korres, A.M.N., Aquije, G.M.D., Buss, D.S., Ventura, J.A., Fernandes, P.M.B. and Fernandes, A.A.R. (2013) Comparison of biofilm and attachment mechanisms of a phytopathological and clinical isolate of Klebsiella pneumoniae subsp. pneumoniae. Sci. World J., 2013: 1-6. Article ID 925375 .

9. Rathore, S.S., Cheepurupalli, L., Gangwar, J., Raman, T. and Ramakrishnan, J. (2019) Biofilm of Klebsiella pneumoniae minimize phagocytosis and cytokine expression by macrophage cell line. bioRxiv, https://doi.org/10.1101/623546.

10. Lenchenko, E., Blumenkrants, D., Sachivkina, N., Shadrova, N. and Ibragimova, A. (2020) Morphological and adhesive properties of Klebsiella pneumoniae biofilms. Vet. World, 13(1): 197-200.

11. Li, J., Fu, Y., Wang, J.Y., Tu, C.T., Shen, X.Z., Li, L. and Jiang, W. (2010) Early diagnosis and therapeutic choice of Klebsiella pneumoniae liver abscess. Front. Med. China, 4(3): 308-316.

12. Jun, J.B. (2018) Klebsiella pneumoniae liver abscess. Infect. Chemother., 50(3): 210-218.

13. Shon, A.S., Bajwa, R.P.S. and Russo, T.A. (2013) Hypervirulent (hypermucoviscous) Klebsiella pneumoniae: A new and dangerous breed. Virulence, 4(2): 107-118.

14. Gameel, A.A., El Sanousi, S.M., Al Nawawi, F. and Al Shazly, M.O. (1991) Association of Klebsiella organisms with pulmonary lesions in sheep. Rev. Elev. Med. Vet. Pays Trop., 44(2): 161-164.

15. Jang, S., Wheeler, L., Schrader, K.N., Carey, R.B., Jessup, D., Jensen, B., Colegrove, K., Crandall, C.M. and Gulland, F.M.D. (2010) Pleuritis and suppurative pneumonia associated with a hypermucoviscosity phenotype of Klebsiella pneumoniae in California sea lions (Zalophus californianus). Vet. Microbiol., 141(1-2): 177-174.

16. Seguel, M., Gottdenker, N.L., Colegrove, K., Johnson, S., Struve, C. and Howerth, E.W. (2017) Hypervirulent Klebsiella pneumoniae in California sea lions (Zalophus californianus): Pathologic findings in natural infections. 
Vet. Pathol., 54(5): 846-850.

17. Ghanem, M.M., Yousif, H.M., Helal, M.A.Y., El-Raof, Y.M.A. and El-Attar, H.M. (2015) Comparative therapeutic effect of three types of antibiotics on pneumonia associated with klebsiella pneumoniae in Boer goats. BMJV. 29 (1): 74-84.

18. Dorothy, K.S., Shafarin, M.S., Geethamalar, S. and Roseliza, R. (2019) A pathological case of Klebsiella pneumoniae infection in colony of dusky leaf monkey (Trachypithecus obscurus). Malays. J. Vet. Res., 10(2): 68-78.

19. Chehabi, C.N., Nonnemann, B., Astrup, L.B., Farre, M. and Pedersen, K. (2019) In vitro antimicrobial resistance of causative agents to clinical mastitis in Danish dairy cows. Foodborne Pathog. Dis., 16(8): 562-572.

20. Francis, M. and Ameh, J. (2015) Aerobic bacteria isolated from pneumonic lungs of cattle slaughtered at Maiduguri Municipal abattoir in Borno State, Nigeria. Vom J. Vet. Sci., 10(1): 20-26.

21. Darsana, I.G.O., Dibia, I.N. and Mahatmi, H. (2015) Detection of Mycobacterium bovis and Klebsiella pneumoniae at bali cattle slaughterhouse by culture analysis and PCR. J. Ilmu Kesehatan Hewan, 3(2): 51-54.

22. Chander, Y., Ramakrishnan, M.A., Jindal, N., Hanson, K. and Goyal, S.M. (2011) Differentiation of Klebsiella pneumoniae and $K$. oxytoca by multiplex polymerase chain reaction. Int. J. Appl. Res. Vet. Med., 9(2): 138.

23. Zhou X. and Moore B. (2017) Lung section staining and microscopy. Bio Protoc., 7(10): e2286.

24. He, Y., Guo, X., Xiang, S., Li, J., Li, X., Xiang, H., He, J., Chen, D. and Chen, J. (2016) Comparative analyses of phenotypic methods and 16S rRNA, khe, rpoB genes sequencing for identification of clinical isolates of Klebsiella pneumoniae. Antonie Van Leeuwenhoek, 109(7): 1029-1040.

25. Paczosa, M.K. and Mecsas, J. (2016) Klebsiella pneumoniae: Going on the offense with a strong defense. Microbiol. Mol. Biol. Rev., 80(3): 629-661.

26. Karmakar, S., Bhattacharya, S., Karmakar, S. and Rai, D.K. (2020) Extensively drug-resistant Klebsiella pneumoniae: A case report. J. Acute Dis., 9(1): 40-42.

27. Sinha, R., Panjabi, C., Varma, M., Vijayan, V.K. and Shah, A. (2003) Chronic Klebsiella pneumoniae in an immunocompetent host. J. Assoc. Physicians. India, 51: 306-308.

28. Bengoechea, J.A. and Sa Pessoa, J. (2019) Klebsiella pneumoniae infection biology: Living to counteract host defences. FEMS Microbiol. Rev., 43(2): 123-144.

29. Iwasaki, A., Foxman, E.F. and Molony, R.D. (2017) Early local immune defences in the respiratory tract. Nat. Rev. Immunol., 17(1): 7-20.

30. Ricciotti, E. and Fitzgerald, G.A. (2011) Prostaglandins and inflammation. Arterioscler. Thromb. Vasc. Biol., 31(5): 986-1000.

31. Zhang, J., Alcaide, P., Liu, L., Sun, J., He, A., Luscinskas, F.W. and Shi, G.P. (2011) Regulation of endothelial cell adhesion molecule expression by mast cells, macrophages, and neutrophils. PLoS One, 6(1): 1-10.

32. Chavakis, T. (2012) Leucocyte recruitment in inflammation and novel endogenous negative regulators thereof. Eur. $J$. Clin. Invest., 42(6): 686-691.

33. Herrero, R., Sanchez, G. and Lorente, J.A. (2018) New insights into the mechanisms of pulmonary edema in acute lung injury. Ann. Transl. Med., 6(2): 32.

34. Jamal, M., Ahmad, W., Andleeb, S., Jalil, F., Imran, M., Nawaz, M.A., Hussain, T., Ali, M., Rafiq, M. and Kamil, M.A. (2018) Bacterial biofilm and associated infections. J. Chin. Med. Assoc., 81(1): 7-11.

35. Azizi, S., Korani, F.S. and Oryan, A. (2013) Pneumonia in slaughtered sheep in South-Western Iran: Pathological characteristics and aerobic bacterial aetiology. Vet. Ital., 49(1): 109-118.

36. Wallace, W.A.H., Fitch, P.M., Simpson, A.J. and Howie, S.E.M. (2007) Inflammation-associated remodelling and fibrosis in the lung-a process and an endpoint. Int. J. Clin. Exp. Pathol., 88(2): 103-110.

37. Chua, F., Gauldie, J. and Laurent, G.J. (2005) Translational review pulmonary fibrosis searching for model answers. Am. J. Respir. Cell Mol. Biol., 33(1): 9-13.

38. Knudsen, L., Ruppert, C. and Ochs, M. (2017) Tissue remodelling in pulmonary fibrosis. Cell Tissue Res., 367(3): 607-626.

39. Jantz, M.A. and Antony, V.B. (2006) Pleural fibrosis. Clin. Chest Med., 27(2): 181-191.

40. Estell, K.E., Young, A., Kozikowski, T., Swain, E.A., Byrne, B.A., Reilly, C.M., Kass, P.H. and Aleman, M. (2016) Pneumonia caused by Klebsiella spp. in 46 horses. J. Vet. Intern Med., 30(1): 314-321.

41. Russell, R.E.K., Thorley, A., Culpitt, S.V., Dodd, S., Donnelly, L.E., Demattos, C., Fitzgerald, M. and Barnes, P.J. (2002) Alveolar macrophage-mediated elastolysis: Roles of matrix metalloproteinases, cysteine, and serine proteases. Am. J. Physiol. Lung Cell. Mol. Physiol., 283(4): 867-873.

42. Gharib, S.A., Manicone, A.M. and Parks, W.C. (2018) Matrix metalloproteinases in emphysema. Matrix Biol., 73: 34-51. 